\title{
Front Matter: Volume 10289
}

, "Front Matter: Volume 10289," Proc. SPIE 10289, Advanced Materials for Optics and Precision Structures: A Critical Review, 1028901 (28 July 1997); doi: $10.1117 / 12.2284584$

SPIE Event: Optical Science, Engineering and Instrumentation '97, 1997, San Diego, CA, United States 


\section{Contents}

vii Preface

FUNDAMENTALS AND ADVANCED APPLICATIONS OVERVIEW

3 Advanced materials: an overview [CR67-01]

R. A. Paquin, Advanced Materials Consultant

19 Advanced applications: an overview [CR67-02]

J. B. Breckinridge, Jet Propulsion Lab.

MATERIAL AND PROCESS OPTIONS: SILICON

AND SILICON CARBIDE

29 Thermophysical properties of optical silicon [CR67-04]

W. A. Goodman, W. J. Schafer Associates, Inc.

53 CERAFORM SiC: roadmap to 2 meters and $2 \mathrm{~kg} / \mathrm{m}^{2}$ areal density [CR67-05]

M. A. Ealey, J. A. Wellman, Xinetics, Inc.; G. Q. Weaver, Jerico

71 Optics applications of chemical vapor deposited $\beta-S i C$ [CR67-07]

J. S. Goela, M. A. Pickering, Morton International, Inc.

MATERIAL AND PROCESS OPTIONS: GLASS, SAPPHIRE, AND COMPOSITES

107 ULE: zero expansion, low density, and dimensionally stable material for lightweight optical systems [CR67-08]

S. T. Gulati, M. J. Edwards, Corning, Inc.

137 Current status of sapphire for optics [CR67-09]

F. Schmid, C. P. Khattak, M. B. Smith, D. M. Felt, Crystal Systems, Inc.

159 Ultralightweight composite mirror technology [CR67-10]

E. P. Kasl, D. A. Crowe, Composite Optics, Inc.

MATERIAL AND PROCESS OPTIONS: BERYLLIUM, NICKEL, AND ALUMINUM

179 Electroless nickel for optical applications [CR67-11]

D. L. Hibbard, Corning OCA

206 Current status of optical grade sputtered, bare beryllium, and nickel-plated beryllium [CR67-12]

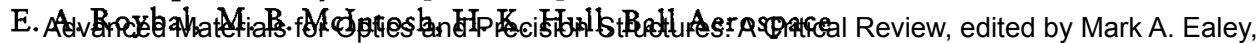
Regqted.hRzdbigieshorep6.B. Parsonage, Proc. of SPIE Vol. 10289 (CR67), 1028901 - @ (1997) 2017 SPIE CCC code: 0277-786X/17/\$18 · doi: 10.1117/12.2284584 
236 Development of aluminum beryllium for structural applications [CR67-13]

T. B. Parsonage, Brush Wellman, Inc.

\section{OPTICAL PROCESSING OPTIONS}

251 Precision optics fabrication using magnetorheological finishing [CR67-16] D. Golini, QED Technologies, LLC; S. D. Jacobs, Ctr. for Optics

Manufacturing; W. Kordonski, P. Dumas, QED Technologies, LLC

\section{SYSTEMS APPLICATIONS: SPACE BASED}

277 ITT'T: a state-of-the-art ultralightweight all-Be telescope [CR67-17]

D. R. Coulter, S. A. Macenka, Jet Propulsion Lab.; M. T. Stier, Hughes

Danbury Optical Systems, Inc.; R. A. Paquin, Advanced Materials Consultant

297 Beryllium structure meets strength, stability, and thermal performance requirements of MODIS instrument [CR67-18]

J. R. Neumann, A. L. DeForrest, T. E. Wolverton, T. S. Pagano, Hughes

Aircraft Co., K. Smith, Brush Wellman, Inc.

\section{SYSTEMS APPLICATIONS: GROUND BASED}

327 VLT secondary mirror: a report [CR67-20]

R. Geyl, M. Cayrel, REOSC (France)

339 Optical substrate materials for synchrotron radiation beam lines

[CR67-21]

M. R. Howells, Lawrence Berkeley National Lab.; R. A. Paquin, Optical Sciences Ctr./Univ. of Arizona

373 Deuterium-fluoride uncooled optics at HELSTF [CR67-22]

A. R. Marrujo, U.S. Army Space \& Strategic Defense Command; C. Lieto, W.J. Schafer Associates, Inc.; P. J. Pomphrey, TRW, Inc.; J. E. Rudisill, Star Optics Inc. 


\section{Preface}

This conference is the direct successor to the 1995 and 1996 conferences with similar titles and is an attempt to bring together the various advanced materials technologies that have been introduced into optical systems in the last decade. While participation by some segments of the industry could not be obtained-a bad thing; it was due to heavy workloads-a good thing.

As in past conferences, beryllium and silicon carbide continue to be the materials described in the greatest number of papers. However, papers on silicon, sapphire, and composites for high energy lasers and synchrotron beam lines help to set this conference apart from previous years. The papers on optical finishing of these advanced materials add a dimension previously missing.

We wish to thank the authors for their participation and for making this volume a true critical review of the advanced materials technology for optics and precision structures.

Mark A. Ealey

Roger A. Paquin Thomas B. Parsonage 